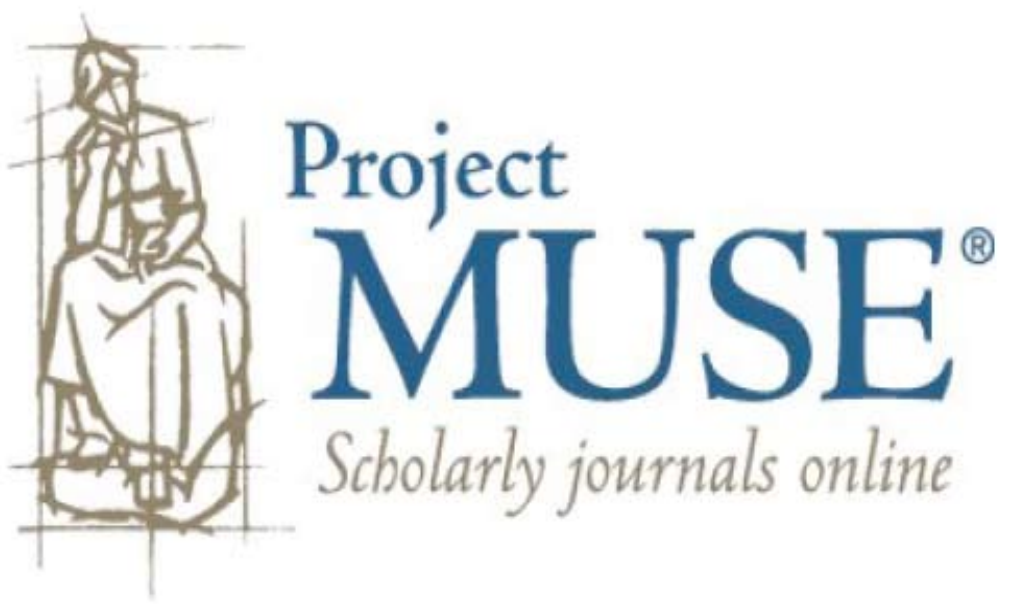




\title{
Play It Again, Sam Weller: New Digital Audiobooks and Old Ways of Reading
}

\author{
Matthew Rubery
}

Ahem. The speaker is about to read aloud Nancy's murder, a brutal tableau from Oliver Twist (1837-39) ritually performed before the public since Dickens' first recitation of this scene at St. James's Hall as part of a Farewell Tour in 1869. The 'Murder', as the author preferred to call it, would soon become part of Dickens lore for the violence with which it ended the life not only of the novel's heroine but also of the novelist himself. ${ }^{1}$ The 'Sikes and Nancy' episode begins with the narrator's voice as one of the boy thieves is instructed to 'dodge' a young woman through the streets of London. The ensuing voices are those of Fagin ('my dear'), Bolter ('Oh Lor!'), and Sikes ('Wot now?'), whose Cockney accents are performed in markedly different registers from that of the preceding narrator. ${ }^{2}$ In fact, each of the characters is set apart by a distinct sound to ensure that audiences can tell who is speaking without access to the written script. The prompt copy used by Dickens for this scene signals the building momentum toward Sikes' terrible act of violence with the marginal stage direction ' $X X$ Murder coming $X X{ }^{3}{ }^{3}$ This is the moment during the recitation when Dickens was said by spectators to have flung aside the script in order to perform the scene from memory. ${ }^{4}$ The audience for the performance has little choice but to sit back and wait for the impending murder since the pace of narration is controlled entirely by the speaker, not the auditor. It is a tense wait. The recitation of a scene that takes a mere ten minutes to read silently to one's self can take upwards of forty minutes when read aloud before an audience. Although both experiences might make the flesh creep, reading the novel in silence is a very different experience from that of listening to Nancy's murder.

Now that Nancy's murder has caught your ear, let me assure you that this is not another account from an ear-witness to one of the nearly 500 public readings given by Dickens to audiences across England and America. ${ }^{5}$ There is no lectern, maroon backcloth, or blaze of gaslamps 
set up for this reading; no magisterial bearded figure in evening dress; and certainly no mesmerising eye contact between orator and audience. Instead, this is an account of listening to one of a dozen recordings of Dickens' novel readily available to twenty-first-century audiences in the form of digital audiobooks - online 'talking books'. At no point in history has it been so easy to listen to the reading aloud of Victorian literature. The reader for this particular performance is not Dickens but one of those inspired by him, from amateur enthusiasts to professional actors: Martin Jarvis, Anton Lesser, Alex Jennings, Nadia May, Fabio Camero, Miriam Margolyes, Flo Gibson, the St. Charles Players, and many other first-time readers. Whereas the majority of audio books marketed today continue to rely on promotional tools designed for print, the publisher's blurb for this recording emphasises what is most distinctive about the audiobook format: 'Hear Dickens' gift for social commentary in this classic story of the poor orphan, Oliver'. ${ }^{6}$ This is a double invitation - 'Hear Dickens' gift' - to listen to the tale being read aloud as well as to the latent aurality of a literary narrative itself designed as much for the ear as the eye.

The growing popularity of audiobooks over the last decade means that literary critics may no longer be able to turn a blind eye or a deaf ear, in this case - to the ways in which oral delivery influences the reception of literature. Digital audio may compel those of us accustomed to silent reading to heed recent calls to refine our skills in 'close listening'. ${ }^{7}$ The following discussion will consider the potential impact new digital audio technology is having over the way we think about literature and its reception. To do so, this piece will introduce the latest audio innovations in as straightforward a manner as possible for those who may be unfamiliar with or even slightly anxious about technology. It will go on to suggest why recent improvements to the audiobook format should be of particular relevance to anyone interested in the nineteenth century. My intent will be to trace a number of continuities between today's reading practices and the presumably outdated forms of reading aloud favoured by the Victorians. As the title of this piece indicates, one unexpected consequence of the new digital audio has been to bring back old ways of reading, specifically the practice of reading aloud associated in the popular imagination with the Victorian family. Whether or not it is true that the audiobook is the latest step in the long process of commodifying literature, this development presents us with an opportunity to reflect on how our own attitudes toward reading aloud have evolved since a nineteenth-century inventor first imagined a 'talking book' capable of preserving the voices of eminent Victorians. 
This piece will conclude with a consideration of the ways in which practices of reading aloud yesterday and today differ from one another by comparing the changing roles of narrator, reader, and listener. In other words, this essay proposes that new digital audio does not simply enable us to hear literature - it enables us to hear it in new ways.

The term 'reading' has never been a simple one when used to describe the behaviour of the Victorians. The persistent identification of reading with a speechless act of decipherment remains something of a reflex among today's literary scholarship. ${ }^{8}$ The most familiar rendition of novel reading in Victorian England emphasises silence, solitude, and introspection, a model of the individual reader closest to our own antisocial experience of reading books. For obvious reasons, it is difficult to dislodge the modern conception of fiction as a predominantly solitary recreation as opposed to a communal pastime. Images of Jane Eyre encased in a window seat with a copy of Bewick's History of British Birds or of David Copperfield on his bed reading as if life depends on it are far more likely to be evoked by today's readers as analogues for their own experience than would equally iconic images of communal reading such as Dickens' Mr. Sloppy, who can 'do the police in different voices' when reading aloud from the newspaper. ${ }^{9}$ Certainly interiorised acts of reading were a vital part of life in the nineteenth century, but to emphasise this reading experience to the exclusion of one better described as vocal, gestural, and spectacular would be to privilege our own reflection over a manner of reading distinctly Victorian. There is no shortage of anecdotes to challenge assumptions that reading was first and foremost a private experience for those living in the nineteenth century. One might recall the young Henry James hidden under a tablecloth to hear instalments of David Copperfield read aloud by a cousin until his sobs at the Murdstones' abuse give away the hiding place. ${ }^{10}$ Notice how in this instance it is the adults rather than the children who gather together for a bedtime story. This was likewise the case with an illiterate charwoman who, despite not being able to read herself, attended monthly readings of Dombey and Son at a local snuff shop. ${ }^{11}$ Many novels, whether in instalments, serialization, or volume format, would have had listening audiences like the James family or the charwoman instead of reading audiences. To put it another way, there was a vast readership that would have heard rather than read these narratives. Although this may be the era during which Great Britain became a 'reading nation', we should not forget the extent to which it remains a 'listening nation' to this very day. ${ }^{12}$ 
More than any other field of inquiry, Dickens scholarship has contributed to our understanding of the oral recitation of literature through its meticulous efforts to document the public readings. ${ }^{13}$ Malcolm Andrews' recent work on this topic, for example, uses dramatic reconstructions from eyewitness accounts to bring before our ears 'audio-visual Dickens', the virtuoso performer whose mesmerising recitals in front of live audiences elicited a wide range of physical responses, from fits of laughter to fainting spells. ${ }^{14}$ Andrews makes a distinction throughout the study between capitalised 'Reading', the act of public recitation, and lower-case 'reading', the private practice overwhelmingly taking place in silence today. The manoeuvre does as much to dispel confusion as to foreground the degree to which the former meaning has been superseded by the latter. Reviving this bygone ambience requires us not only to read aloud ourselves but to reconstruct as far as possible the public culture drawn upon by such performances. Deborah Vlock has proposed the term 'imaginary text' to approximate such an experience of reading informed by a wide variety of extratextual entertainment like the theatre. ${ }^{15}$ In fact, it is striking how many scholars who work on Dickens' public readings attribute their scholarly interest in the subject to childhood experiences of being read aloud to by family members. ${ }^{16}$ If there is a sense in which no one ever reads a Dickens plot for the first time, it is because that story has been heard to some extent before it has been read. A Christmas Carol is only the most obvious example of such a twiceheard tale.

Victorian scholarship itself has taken an 'aural turn' over the last decade by way of a number of studies revisiting the period's attitudes toward sound. ${ }^{17}$ This increased auditory awareness has renewed interest in the many ways in which literature of the long nineteenth century has been shaped by the surrounding 'soundscape', an acoustic environment discernible as a field of study just as might be done with a landscape. ${ }^{18}$ As these studies remind us, modern approaches to sound themselves originated in the late nineteenth century with the advent of such influential technologies as Hermann von Helmholtz's resonator, Alexander Graham Bell's telephone, and Thomas Edison's phonograph. The present moment is not dissimilar to that faced by an earlier generation in trying to determine the most advantageous way in which to use the available tools. Hence the introduction of new sound technologies in our own time may be productively compared with the reaction to new sound technologies by the Victorians.

To make such a comparison, let us return to the moment when Thomas Edison first pitched the potential benefits of the 
phonograph to an audience unfamiliar with the device. In the pages of the North American Review in 1878, Edison's essay 'The Phonograph and its Future' proposed the following applications - some now familiar, others wildly optimistic - for his invention: dictation, education, advertising, letter writing, courtroom testimony, elocutionary instruction, musical entertainment, family archives, mechanical dolls, alarm clocks, public speeches, and telephone transcripts. The charitable potential of the device could be put to use through books recorded for the blind, the bed-ridden, and even gentlefolk without a spare hand. 'Phonographic books' were an inevitable step in Edison's ears: 'The advantages of such books over those printed are too readily seen to need mention. Such books would be listened to where now none are read'. ${ }^{19}$ In other words, the phonographic book would not simply act as a substitute for its printed counterpart but expand its market to new listeners - the very goal of retailers promoting 'Get Caught Listening' campaigns on public transport today. Edison was among those who recognised the degree to which audio recordings could be more pleasurable when read by an elocutionist rather than an ordinary reader. A followup piece by Edison published ten years later under the title 'The Perfected Phonograph' revisited the topic of the 'unlimited' amount of entertainment to be made available in this way:

Any one sitting in his room alone may order an assorted supply of wax cylinders inscribed with songs, poems, piano or violin music, short stories, anecdotes, or dialect pieces, and, by putting them on his phonograph, he can listen to them as originally sung or recited by authors, vocalists and actors, or elocutionists'. ${ }^{20}$

The solitary reader would thereby have at his fingertips a wide selection of spoken entertainment without needing to leave the house. The whole of Dickens' Nicholas Nickleby, Edison proposed by way of example, would fit comfortably onto four eight-inch cylinders. ${ }^{21}$ This entertainment would reach beyond the visually impaired to anyone who preferred listening over reading.

The audiobook has assumed various formats during its evolution from wax cylinder to vinyl record to cassette tape to compact disc to digital file. While Edison's enthusiasm for 'phonographic books' may have fallen on deaf ears, literature recorded for gramophones was tested as early as the 1920s by the Royal National Institute for the Blind (RNIB) for the benefit of soldiers injured during World War One. In 1935, the RNIB's Talking Book Service delivered its first audiobooks (Agatha Christie's The Murder of Roger Ackroyd and Joseph Conrad's 
Typhoon) to blind and partially sighted people. By 2002, the service that had begun recording on 12-inch discs made from shellac and, later, on cassette tapes had switched to digital recording through the use of specialised long-playing compact discs. The Talking Book Service today has issued over 75 million audiobooks to over 2 million people since its inception and currently holds the largest library of unabridged audio books in the UK. ${ }^{22}$ It is worth pausing to ask why a service that has been around for nearly 75 years would be cited here as an example of 'new media'. After all, the audiobook itself is not a new medium. My response is that digital technology is expanding the audiobook market beyond recordings initially intended for the visually impaired to recordings for readers of all kinds.

Let me elaborate on the difference digital technology has made by turning our attention to the ways in which digital audiobooks are once again making Britain a listening nation. The present moment is a potential tipping point in the use of audiobooks because the cumbersome formats of cassette tapes and compact discs need no longer make listening to them a chore. To take an extreme case, Tolstoy's War and Peace requires 45 cassettes when spoken by Walter Zimmerman (1982) or 50 compact discs when told by Neville Jason (2006). These cumbersome formats showed little improvement over Edison's wax cylinders in terms of convenience - it may be easier to bring back the live orator in such cases than to swap discs that many times. The inconvenience of these productions should make it clear why audiobooks have remained a niche interest until the arrival of digital audio made it possible to download virtual recordings. The ease of doing so need not concern us here. What matters instead is the rise in the number of people listening to audiobooks now that digital technology has made them more readily available. While audiobooks are still responsible for only a small fraction (4-10\%) of the total book publishing market, they accounted for sales of $£ 71.4$ million in the United Kingdom in 2005 according to industry figures compiled by the Audiobook Publishing Association. The figures are even larger in the United States, where a consumer survey conducted by the Audio Publishers Association in 2006 reported that nearly a quarter $(24.6 \%)$ of the population had listened to at least one audiobook during the previous year. ${ }^{23}$ These numbers, while relatively small in comparison with conventional book sales, still account for a substantial number of readers as well as an upward trajectory. As the number of overall readers continues to decline, audiobook use is among the minority of reading practices found to be increasing general literacy. ${ }^{24}$ 
Although it would be easy to overstate the degree to which technology changes the way we communicate, there is nevertheless compelling evidence of its influence over the way people read that should not go unheard. ${ }^{25}$ Advances in audio technology have the potential to change the way we think about reading practices for two reasons. The first is that digital audio will turn more readers into listeners. Listening to audiobooks is gaining unprecedented popularity due to the ease with which people are now able to do so through portable listening devices (e.g., iPod, Sony Walkman, or even a mobile phone). Audiobooks nearly always use platforms designed for music, which makes the consumption of such devices in the last decade pivotal to their success. In 2006, there were an estimated 7.3 million MP3 players in Britain; industry analysts predict that approximately 500 million people worldwide will have portable music players by $2010 .{ }^{26}$ Listeners can now choose between the traditional compact disc or audio downloads to these devices straight from websites. In a 2006 opinion piece for The Bookseller, marketing consultant Damian Horner asked whether publishers have mistakenly devoted their resources to the electronic book instead of the audiobook, or the 'e-book' rather than the 'a-book':

Are we all looking the wrong way? While everyone gets obsessed with e-books, is the future of mass market books somewhere else entirely? Is the biggest impact of digital technology actually going to be the rebirth of something that has been around for years - the humble and much maligned audiobook ? $^{27}$

Edison's optimism may be making a comeback. The key change in attitude has been to recognise that the audiobook is a distinct medium in its own right rather than a poor relative of the printed book. There are even signs that the digital option is at last encouraging use of a medium that has been around for decades.

The leading providers of spoken entertainment on the internet to date have been Audible.com and its subsidiary Audible.co.uk, which provide audio editions of books, magazines, and even daily newspapers through such packages as The Times Audio Digest (wrongly predicted by Edison to be one of the services provided by the phonograph).$^{28}$ For those wary of purchasing audiobooks, the lending library itself endures in the alternative form of online rental services. Organizations such as Simply Audiobooks enable members to rent audiobooks on compact discs through an annual subscription similar to the way many people borrow DVDs from online rental services, surely the twenty-first-century equivalents of Mudie's Circulating Library. Many 
brick-and-mortar libraries themselves now stock digital audio narratives for download by patrons who no longer need to visit the building to obtain their books. At the same time, other providers of spoken word content are recruiting listeners through technology suitable even for the techno-phobes among us. Macmillan recently became the first UK publisher to produce battery-operated 'plug and play' listening devices capable of storing up to fifty hours of spoken-word content. These devices will enable the digitally-challenged to purchase portable players with an audiobook already installed - a simplicity reminiscent of another Victorian invention, the Kodak camera, whose popularity was assured by the motto: 'You press the button, we do the rest'. ${ }^{29}$

Once deterred by high prices and unwieldy formats, publishers likewise now seek new ways of marketing audiobooks through listening posts in retail shops and online ventures such as Spoken Network, which has the backing of nearly fifty international publishers including BBC Audiobooks. The marketing lingo used by these publishers is just beginning to shed its biblio-centric roots through advertisement campaigns in which the 'sound review' replaces the book review, summer reading gives way to 'summer listening'. One publisher website using audio to market both print and talking books is the HarperCollins Digital Media Café, whose very name strives to align its virtual forum with the literary public sphere originating among the coffee houses of eighteenth-century Europe..$^{30}$ The degree to which we are willing to surrender viva voce conversation to the digital voice' is being tested by such online ventures. An extreme case is AudioBookHouse.com, which relies on text-to-speech conversion technology in place of a human narrator. Readers may cringe at the development, worrying we are one step away from having books read aloud to the family by a robot instead of paterfamilias. Yet this cybervoice is little more than the latest step in the long transition from human narrator to phonographic voice in absentia to the virtual voice of technology.

The voices behind commercial audiobooks from major publishing houses perpetuate the tradition of staged readings by celebrated actors more so than the domestic pastime of reading aloud in the Victorian parlour. Amateur entertainments showed no lack of enthusiasm, but rarely did one find the professional skill exhibited by, say, Henry Irving's recitation of Thomas Hood's 'The Dream of Eugene Aram'. ${ }^{31}$ The hazards of amateur poetry recitals at this time are evident from the negative imperatives addressed to the common reader by Edward W. Cox's manual on The Arts of Reading, Writing and Speaking (1863): 'You must not sing it; you must not chant it; you 
must not drawl it ... you must not make prose of it'. ${ }^{32}$ As manuals on the art of public speaking attest, the tradition of reading aloud for public and private audiences was well established by the time Dickens took to the stage to give his first public reading of $A$ Christmas Carol for charity in December 1853. Charles Mathews, Albert Smith, Sarah Siddons, and Fanny Kemble were but a few of the celebrities distinguished for their reading abilities. ${ }^{33}$ A homologous distinction between amateur and professional endures within today's recording industry, in which the majority of narrators have previous theatre training or commercial voice-over experience. 'Voice actor' is the title given to these readers as a way of aligning them with other categories of professional performers and, more importantly, distancing them from uncredentialed enthusiasts. Occasionally readers are themselves celebrities (for example, James Mason or Jeremy Irons reading Lolita) whose name recognition promises to boost sales. Few voice actors are as fortunate as Gerald Charles Dickens to have inherited his greatgreat-grandfather's name as a way of attracting audiences to dramatic readings of $A$ Christmas Carol during his Tenth Anniversary Tour in 2005.

The distinction between professional and amateur readers brings us to the second reason that digital audio technology has the potential to change the way we think about reading practices. The discussion up to this point has explained how digital audio will turn more of us into listeners. The second part of my argument is that this same technology will turn more of us into narrators. DIY recording software makes it simpler than ever before for individuals to record their own audiobooks. This is particularly easy to do through the use of the podcast (a portmanteau word combining the name of Apple's 'iPod' and the term 'broadcast'), a digital audio file distributed over the internet to one's computer. ${ }^{34}$ The podcast is in many ways the audio equivalent of the blog. Now anyone can record an audiobook: all you need is a computer, recording software, and your own voice. ${ }^{35}$ As we have seen, professional voice actors may account for the majority of commercial recordings, but this in no way detracts from the groundswell of audio vérité coming from amateurs. There has been something approximating a grass-roots movement during the last decade to provide free audio recordings of out-of-copyright literature. To take one example, the website www.LibriVox.org (derived from the Latin terms for 'BookVoice') began as an experiment to distribute audiobooks already in the public domain - what it describes as 'acoustical liberation'. The site is founded entirely on voluntary contributions from amateur readers without previous experience with 
acting, recording, or public speaking. ${ }^{36}$ The site takes the majority of its scripts from Project Gutenberg, the largest single collection of free electronic books. Just as cinema has long favoured the straightforward plots of nineteenth-century novels for the screen, so have spokenword entertainers turned to these same narratives for their audibility. Readers of this article may even be tempted to volunteer to record a chapter themselves, thereby editing in the guise of auditing.

Audiobooks are still very much books rather than scripts in the hands of many amateur readers on these websites. As patrons of LibriVox have noted, amateur readings tend to pay closer attention to the text as a written narrative than do professional recordings, which often blur the line between book and performance (many commercial titles include the tag 'dramatised' to distinguish them from straightforward readings) ${ }^{37}$ Scrupulous adherence to the printed text is one of the characteristics distinguishing these recordings from dramatizations found on radio programmes. ${ }^{38}$ Advice for firsttime readers on how to read aloud is available through the LibriVox style guide, whose recommendations include making yourself comfortable with the sound of your own voice, looking slightly upward to give the voice more timbre, and, most importantly, controlling the pace in order to engage the listener. Much of this advice will be familiar to actors who have worked with a voice coach to improve such aspects of their delivery as 'verbal muscularity'. ${ }^{39}$ Perhaps the most consequential decision to be made when recording an audiobook is how far to take 'voice characterization', the narrator's performance of varied vocal registers to represent different characters in the narrative. This can be challenging for narrators reading stories outside the range of their own biography and may even call for a counterintuitive solution; for instance, male narrators often have more success speaking female parts in a whisper rather than a falsetto. This is another performance problem first addressed by the orators of preceding generations. One has only to revisit Dickens' cues - 'Shudder', 'Mystery', 'Terror To The End' - in the reading scripts to see how seriously their delivery was taken. ${ }^{40}$ (Dickens' friend Charles Kent described the scripts as 'cobwebbed' by markings from the author's hand. $)^{41}$

In addition to influencing the way we think about our own reading practices, digital audio presents an opportunity to instil in students a degree of self-awareness about how their reading habits differ from those of previous generations. ${ }^{42}$ 'Talking books' are one of the most effective ways to get students talking about the reception of Victorian literature. One way to accomplish this is by assigning students to create their own recordings of a Victorian narrative. 
The audio-editing software mentioned earlier in this article makes recording an audiobook easy to do (they will no doubt be more comfortable with this than many of us) and to distribute to other students for proof-listening: is this how they imagine a given character would sound? While such a question may seem impressionistic, the Victorians themselves were the first to debate any disparity between printed and spoken versions. This was only too obvious in the dissatisfaction expressed by many auditors with Dickens' portrayal of crowd-favourite Sam Weller during the trial of Bardell vs. Pickwick from The Pickwick Papers. Charles Kent and Kate Field note how applause from the audience invariably greeted Serjeant Buzfuz's announcement: 'Call Samuel Weller'. ${ }^{43}$ Yet the following response by an unnamed American spectator captures the subsequent deflation felt by many in the crowd: 'that ain't my idea of Sam Weller, anyhow' ${ }^{44}$ Field attributes such disappointment to unreasonably high expectations of the comic character taken from the page. ${ }^{45} \mathrm{~W}$. P. Frith even claims to have advised the author to replace Sam's 'sneaking' way of talking with a delivery in which his wit fires forth 'like pistol-shots' ${ }^{46}$ George Dolby observed that the liberal improvisations made to the Pickwick scripts by Dickens ensured they 'were regarded more in the light of a new edition, direct from the author, than anything else' ${ }^{47}$ Still, the trial scene of Bardell vs. Pickwick remained one of the most popular recitation pieces in Dickens' time. ${ }^{48}$ The audiobook now makes it possible to hear the voice of Sam Weller again and again.

A multimedia approach to Victorian literature may be a foreign tongue to some academics, but it is thought by many to be the lingua franca of today's students. ${ }^{49}$ This fluency with technology stems from years of downloading entertainment, filming with digital cameras, and communicating through mobile phones. Students have little trouble understanding how these devices shape their communication - the way in which the medium is the message, as Marshall McLuhan famously put it - even if they rarely think of Victorian media along the same lines..$^{50}$ Encouraging students to do so may get them to rethink why literature designed by Victorian authors to be read aloud might value such elements as melodrama, sentimentality, or episodic structure to a different degree than would audiences accustomed to the silent reception of literature. The theatricality of this literature also reveals a different approach to thinking about such topics as editorial censorship, or in many cases self-censorship, toward material deemed inappropriate for family audiences since the time of Mrs. Grundy. It will take more than digital technology to increase the audience for Victorian poetry (the reason why this article has emphasised prose), 
but, again, it could be used to emphasise how much of this poetry must be spoken aloud to be understood, especially in dialect poems such as Tennyson's 'The Northern Farmer' or Kipling's 'Tommy'. ${ }^{51}$

As with the first Victorians to use the phonograph, our challenge is to figure out the best way to use this new technology. In this spirit, Denis Donoghue has asked whether digital media may offer a way to recapture the sense of orality inhospitably shoved aside by the coming of print. His response is an ambivalent 'not necessarily'. For Donoghue, new technologies offer only 'secondary orality,' a term borrowed from Walter Ong to describe what might be little more than a simulation of the conditions of oral society. ${ }^{52}$ One derivative form of this orality is to be found in television programmes imitating participatory communities such as book groups without actually bringing readers into contact with other human beings. Worse, audiences may even come to prefer the scripted nature of such virtual formats over unscripted interaction with other readers. This is a familiar narrative of technology as derivative, inauthentic, and belated. But we need not assent to this pessimistic viewpoint as telling the full story. Another way of judging 'secondary orality' might be as a 'second chance' for forms of oral discourse otherwise doomed to extinction. The term 'talking books' expresses just such a gesture to retain the feel of oral culture despite an absence of the very embodied voice that would presumably be its prerequisite. Notice how different the formulation 'talking books' is from its counterpart 'books on tape', a phrase foregrounding the new medium over the old at the risk of finding its appellation obsolete when even newer technologies such as the compact disc come along to replace it. The reading of literature may no longer take place at the hearthside (and here we should be mindful that Dickens himself has been accused of lecturing from the "hearth-manqué ${ }^{53}$ ), but attempts continue nevertheless to find ways of reconstituting the sense of community best represented by the domestic ideal of family storytelling. The most complete recreations take place at the theatre in the tradition of Emlyn Williams, Patrick Stewart, and other actors who performed the readings in front of an audience in homage to Dickens. ${ }^{54}$ Cynicism toward public reading is premised on too firm a contrast between the participatory experience of listening to an individual speaker in close proximity and the supposedly atomistic experience of apprehending a public recital. The contrast between active and passive (often, if misleadingly, corresponding to 'listening' and 'hearing') in such an example is hardly tenable if one considers how active any process of reception can be, whether this involves silent reading of a written text or apprehension of the spoken word - surely 
such recreations as theatre, cinema, and television (the last of which is the most common analogy to the audiobook) are no longer so easily dismissed under the category of passive entertainment.

This is not to say there are no substantial differences between the two modes of reading aloud. The most significant difference may be that reading aloud prior to the twentieth century entailed forms of sociability alongside which reading aloud in the twenty-first century appears antisocial in its separation of the listener from interpersonal relationships long feared to be a consequence of the increasing technologization of society. ${ }^{55}$ Before dismissing this mediated form of sociability, however, we should recall how enthusiastic Victorians themselves were toward the ability of devices such as the telephone and the phonograph to capture voices detached from actual bodies - much of the novelty of the phonograph arose from its capacity to preserve the speaker's posthumous voice ${ }^{56}$ In fact, the Victorians have been charged with initiating the very process of sound commodification whose pace has escalated through modern technology to its current level. The most hostile approach can be found in the techno-skepticism given voice by the Frankfurt School, which casts a wary eye upon the capacity of new media to generate a ceaseless supply of entertainment for mass consumption. ${ }^{57}$ From this perspective, the audiobook replaces the human voice with a simulation or even simulacrum of that voice, a form of pseudo-intimacy used to lull consumers into a manufactured sense of companionship. Such an outlook cautions against overhyping the benefits of technology, but it by no means accommodates the full range of ways through which people experience digital media. Sound reproduction can be deemed inauthentic only when judged against a standard whose historical status is questionable at best. ${ }^{58}$

With these criticisms in mind, it may be more productive to consider the audiobook less as a degraded version of the hearth-reading than as a distinct performance in its own right. There are three key ways in which the audiobook departs from the tradition of reading aloud in the home. First, the hearth-reading was restricted in space. Despite also taking place in public venues such as the theatre or music hall, reading aloud was largely associated with domestic ritual as one of the few shared recreations available in the Victorian household. Expensive, cumbersome books at this time were conspicuously unportable, a far cry from today's pocket paperbacks, and reading aloud by the hearthside commemorated the value of these possessions. By contrast, the audiobook represents what might be thought of as a portable hearth-reading. One has only to recall the manner in which Dickens urged audiences to think of themselves 'like a group of friends, 
listening to a tale told by a winter fire' to see the appeal of this illusory continuity. ${ }^{59}$ This is pertinent since reading aloud today is rarely associated with domestic space at all beyond childhood reminiscences of books before bedtime. The most common venues are now antisocial ones since audiobooks can be absorbed behind the wheel of an automobile in a way that the physical book cannot. (Observe the following slogan for Audible.com: 'audio that speaks to you wherever you are'.) While this will strike some listeners as sensory overload when contrasted with a single leisure activity, others will view this as a way to reclaim personal time from a schedule ruled by public responsibilities. ${ }^{60}$

A second way in which the hearth-reading differs from the audio recording is evident in time constraints. The hearth-reading was akin to a live performance in the sense that it required preparation, coordination, and undivided attention from the entire group. Its continuous pace offers a stark contrast to the punctuated rhythm of the audiobook controlled by the listener. It is a format adapted to the tempo of modern life more so than the hearth-reading, which would probably stretch modern attention spans to breaking point anyway. In other words, the audiobook provides a virtual performance independent of the actual audience. The radio may be seen as a transition between the two modes of performance mentioned to this point in the way it frees the listener from spatial constraints while preserving its own time restraints. Until now, that is. The same advances in digital technology turning the audiobook into more than a coterie medium will likewise make radio programmes, formerly considered an 'ephemeral art form', more widely available to listeners unable or unwilling to adhere to the broadcaster's timetable.$^{61}$ In 2004, for instance, the BBC became the first British broadcaster to make its radio programmes available to the public for free download via digital formats. The radio has been of profound importance over the last century in sustaining a listening culture, though it is only with the advent of digital playback that this content can now reach audiences beyond its fixed time slots.

The third and most crucial difference between the hearth-reading and the audiobook has to do with voice. One might expect the face-to-face encounter established by the hearth-reading to be more intimate than the experience of listening to the disembodied voice of radio. Yet I find the reverse often to be true. For me, the sensation of listening to someone else's voice whispered directly into my ear can be far more intimate than any number of public readings could ever hope to be. Think of the manner in which Dickens strives for 
proximity to the reader through such remarks as 'I am standing in the spirit at your elbow', if not your ear, in A Christmas Carol. ${ }^{62}$ True, the portable player does not present an actual person before you; there is no body movement, no facial expression, and no eye contact. The difference here lies in what might be called ear contact, the unbroken link between voice and ear for which the telephone may be the best analogy. This sensation has been described in synaesthetic terms through an aphorism formulated by Murray Schafer: 'Hearing is a way of touching at a distance'. ${ }^{63}$ Schafer had in mind forms of sociability arising through sonic environments such as concerts, but this is true with many forms of mediated speech - one reason why so many listeners have long favoured the intimacy of radio over visual media. Sound technology has the capacity to create a private acoustic space separating the listener from the surrounding noise of the outside world. Headphones (or what the Victorians knew as 'hearing tubes') in particular can intensify the listening experience by making it possible to attend to minute sonic details that might otherwise go unheard.$^{64}$ Close listening in this manner is only possible with recorded performances of the sort taken for granted by close readers of the printed text. It is in this sense that literature is not just heard but heard in new ways through the use of today's sound reproduction technology.

'Perpetual immediacy' is in fact the aim of voice actor Barbara Rosenblat, who advises her students to recreate as far as possible the childhood experience of hearing stories read aloud. ${ }^{65}$ The very image of the acquiescent child elicits the most common complaint made against the passivity invited by the audiobook. Its critics have questioned the degree of agency required from both Victorian and modern auditors. According to this viewpoint, reading demands active forms of behaviour including decipherment, interpretation, and judgment, whereas merely listening implies a passive state of absorption often described in terms of 'lulling' the reader into an uncritical state of relaxation. As Jason Camlot has observed in one of the few studies to take audiobooks seriously, the degree to which a literary text solicits 'vocalization' by the reader of the printed page has been taken by many to be a fundamental part of the imaginative apprehension of literature. Camlot's study paraphrases the passivity argument in distinctly Victorian terms: 'Like Trilby unconsciously performing the musical mind of the mesmerist Svengali, the sound of the audio book inhibits our own imagination by performing our potential imagining of the text's voice for us' ${ }^{66}$ Other listeners simply complain about how unsettling it can be to find a narrator's voice at 
odds with their own ideas of how that voice should sound. ${ }^{67}$ Yet it is difficult to see why these objections would not apply to all public readings as well as to the easy target of audiobooks, which, for once, cannot speak for themselves. After all, there is no shortage of living authors to disappoint expectant readers with poor recitations of their own work.

As the various impressions of Sam Weller have shown, the most effective way to understand reading aloud may be as an interpretation - what George Dolby referred to in an earlier quotation as 'a new edition' - if not an adaptation of the original printed text. Seen in this way, the reciter supplements the original script by drawing out dramatic aspects of the printed narrative that might otherwise go unheard. Yet even this approach risks too firm a distinction between silent and aural reception that is often untenable when it comes to a style of Victorian literary production for which those boundaries were flexible at best. As is well known, A Christmas Carol and other tales from this period were composed with their spoken recitation in mind. Even an author as removed from the spotlight as George Eliot relied on reading aloud privately to ensure the narrator's voice resembled that of an authentic person. ${ }^{68}$ Such an approach further assumes there to be a single authoritative version from which all subsequent variants may be taken to descend. Varied publication formats from serialization in mass-market periodicals to individual volumes loaned from Mudie's undermine this faith in a single authoritative source. These varied formats comprise changes in text (authorial emendations), paratext (font, layout, prefatory material), and, most importantly, in readership. It is not clear why oral performance of the narrative would differ in kind from these earlier variations in which authors recited their own work. It has often been said that no two Dickens readings were ever the same since there was so much variance between individual performances. To this end, Charles Bernstein has insisted that the poet's performance of the poem - what he designates the 'audiotext' should be granted some equivalence to these other textual variants. ${ }^{69}$ Bernstein's insistence is less original than it may appear since even one of Dickens' own writers - John Hollingshead - referred to the author's readings as 'running, critical commentaries upon his own works'. ${ }^{70}$ Why grant authorial control over the voice inside a reader's head to the printed text but not the spoken text? It is a rare instance in which we still have access to the audiotexts of Victorian poets as in the case of, say, Tennyson's phonograph recording of 'The Charge of the Light Brigade', but we do know from biographical sources how influential such readings could be. ${ }^{71}$ 
While the sound of Tennyson's voice may be lost to us from all but a handful of his readings, we at least have the capacity to hear a range of new voices reading aloud from the work of Victorian authors. This is a moment to be the audience for literary works that lose much of their richness if their speaking voices go unheard. Such quintessentially Victorian preoccupations with the expressiveness of voice, the cadences of language, and vocal improvisation that leave little trace beyond the original delivery are difficult to shut one's ears to when confronted with the audiobook. Like Dickens' Daniel Quilp from The Old Curiosity Shop, we are in a position to take in private scenes from the narrative even as the narrator disavows our right to do so: 'These were not words for other ears, nor was it a scene for other eyes. And yet other ears and eyes were there and greedily taking in all that passed....${ }^{72}$ Our eyes have done much more of the taking in than our ears up to this point. The kinds of reading aloud occasioned by the audiobook will no doubt return our attention to just how much characterization in the Victorian novel happens through speech. It is easy to overlook the degree to which characters in these novels speak a language intimately connected to their social status as members of the urban working-class or the rural squirearchy. Just as facial expression, physical gesture, and attire act as a semiotic index to moral character in the Victorian novel, so do verbal cues from dialect to idiom to syntax tell us what we need to know about characters without ever setting eyes on them. Only by vocalising these expressions through the practice of reading aloud are we assured of appreciating how central voice is as a source of meaning in the Victorian novel.

It should be said that a 'talking article' may have been the most effective way to make the case for digital audio presented here. Regrettably, the market for audio-journals remains a niche one. The printed voice of this article has nevertheless done what it can on paper to suggest how digital audio may influence the way we think about reading practices. As we have seen, one of the most consequential effects of the new digital audio has been to bring back old ways of reading, specifically the practice of reading aloud associated with the nineteenth-century parlour. This is a good thing for Victorianists, who now have an opportunity to transform themselves along with their students into 'Victorian' readers in order to obtain an informed appreciation of that era's ear-catching prose. The audiobook enables us to do so by restoring the easily overlooked dimension of aurality to a literature hitherto received almost entirely in visual terms. Even contemporary fiction bearing little resemblance to the triple-decker novels of the nineteenth century is being received in a manner that 
may have more in common with that of earlier generations than of our own preference for silent reception. At the same time, the kinds of reading aloud permitted by new audio technology at last make close listening a possibility to a degree unheard of for Victorian listeners despite their own pioneering sound reproduction devices. It is time to open our ears to the impact of the audiobook on literary reception now that reading aloud has moved out of the parlour and into the streets. No one is better equipped to do so than those of us interested in Victorian literature, for whom reading aloud has always held a special place in our hearths. This is a plea to give the audiobook an audition in the full sense of the word: a listen, a hearing, a trial performance. A Victorian inventor's wish for a talking book is now a reality: are you listening?

(University of Leeds)

\section{Endnotes}

1. The popular association between Nancy's murder and the author's death is documented by Peter Ackroyd in Dickens (London: Sinclair-Stevenson, 1990), 1039-42. Harry Furniss' illustration 'Charles Dickens Exhausted' best expresses this link by depicting the author's prostrate body underneath a silhouette of the murder scene (Some Victorian Men [London: John Lane; New York: Dodd, Mead and Company, 1924], facing page 194).

2. Charles Dickens, Oliver Twist, ed. Philip Horne (London: Penguin, 2002), 377, 378, 391.

3. Philip Collins, ed., Charles Dickens: The Public Readings (Oxford: Clarendon Press, 1975), 482.

4. Mentioned in the account given by Edmund Yates in 'Mr. Charles Dickens's New Reading', Tinsley's Magazine 4 (Feb 1869), 62.

5. Three of the most influential accounts of the public readings by contemporaries include Charles Kent's Charles Dickens as a Reader (London: Chapman \& Hall, 1872), George Dolby's Charles Dickens as I Knew Him: The Story of the Reading Tours in Great Britain and America, 1866-1870 (London: T. Fisher Unwin, 1885), and Kate Field's Pen Photographs of Charles Dickens's Readings: Taken from Life, ed. Carolyn J. Moss (Troy, New York: The Whitston Publishing Company, 1998).

6. 'Publisher's Summary' for Dickens' Oliver Twist, narrated by Miriam Margolyes (Auburn, California: The Audio Partners Publishing Corp, 2005).

7. The phrase is taken from Charles Bernstein, Close Listening: Poetry and the Performed Word (New York: Oxford University Press, 1998), 4.

8. See Garret Stewart's discussion of the degree to which silent reading itself depends upon the interplay between graphic and phonic articulation, in Reading Voices: Literature and the Phonotext (Berkeley: University of California Press, 1990).

9. Dickens, Our Mutual Friend (New York: Penguin Books, 1971), 246.

10. This anecdote is recalled by James in A Small Boy and Others: A Memoir (London: Gibson Square Books Ltd, 2001), 62. Additional evidence of the diverse reading styles in fact and fiction at this time can be found in Philip Collins, 'Reading Aloud: A Victorian Métier', Tennyson Society Monographs No. 5 (Lincoln: The Tennyson 


\section{Matthew Rubery}

Society, 1972) and Stewart, Dear Reader: The Conscripted Audience in NineteenthCentury British Fiction (Baltimore: Johns Hopkins UP, 1996).

11. Edgar Johnson records this anecdote in Charles Dickens: His Tragedy and Triumph, vol. 2 (London: Victor Gollancz, 1953), 613.

12. The phrase is taken from William St. Clair's study of nineteenth-century print culture The Reading Nation in the Romantic Period (Cambridge: Cambridge University Press, 2004).

13. The best introduction to the readings continues to be Collins' Charles Dickens: The Public Readings. Recent scholarship on this topic is reviewed by Malcolm Andrews, Charles Dickens and His Performing Selves: Dickens and the Public Readings (Oxford: Oxford University Press, 2006).

14. Andrews, viii.

15. Deborah Vlock, Dickens, Novel Reading, and the Victorian Popular Theatre (Cambridge: Cambridge University Press, 1998), 6.

16. For example, see the accounts of hearing Dickens read aloud during childhood given by Vlock, 6, and Paul Schlicke, Dickens and Popular Entertainment (London: Unwin Hyman, 1985), ix.

17. See Peter Bailey's exploratory discussion 'Breaking the Sound Barrier' in Popular Culture and Performance in the Victorian City (Cambridge: Cambridge University Press, 1998), 194-211.

18. See the discussions of auditory experience in John Picker, Victorian Soundscapes (Oxford: Oxford University Press, 2003) and Melba Cuddy-Keane, 'Modernist Soundscapes and the Intelligent Ear: An Approach to Narrative through Auditory Perception', A Companion to Narrative Theory, ed. James Phelan and Peter J. Rabinowitz (Oxford: Blackwell, 2005), 382-98. Picker's keynote address at the 'Victorian Soundscapes' Conference at Leeds University and Trinity and All Saints in March 2007 cites as sonic influences studies as diverse as R. Murray Schafer's The Tuning of the World (New York: Knopf, 1977), Steven Connor's Dumbstruck: A Cultural History of Ventriloquism (Oxford: Oxford University Press, 2000), Jacques Attali's Noise: The Political Economy of Music, trans. Brian Massumi (Minneapolis: University of Minnesota Press, 1985), Friedrich Kittler's Gramophone Film Typewriter, trans. Geoffrey Winthrop-Young and Michael Wutz (Stanford: Stanford University Press, 1999), and Jonathan Sterne's The Audible Past: Cultural Origins of Sound Reproduction (Durham: Duke University Press, 2003). This address and other conference proceedings can be found in Victorian Soundscapes Revisited, ed. Martin Hewitt and Rachel Cowgill, Leeds Working Papers in Victorian Studies, Volume 9 (Leeds Centre for Victorian Studies, 2007), 39-52.

19. Thomas A. Edison, 'The Phonograph and its Future', North American Review 126 (May 1878), 534.

20. Edison, 'The Perfected Phonograph', North American Review 379 (June 1888), 646.

21. Edison, 'The Perfected Phonograph', 646.

22. This account has been gathered from the 'History of RNIB Talking Books' at www.rnib.org.uk/xpedio/groups/public/documents/publicwebsite/public_tbhistory. hcsp (accessed 26 March 2007). My thanks to the staff at the RNIB National Library Service for providing additional information about the Talking Book Service.

23. See the Audio Publishers Association's Audiobook Market Survey: Customer Profile, Usage Patterns, and Experiences available at http://www.audiopub.org/files/public/ 2006ConsumerSurveyCOMPLETEFINAL.pdf. 


\section{New Digital Audiobooks and Old Ways of Reading}

24. Statistical evidence for this shift can be found in the National Endowment for the Arts report 'Reading at Risk: A Survey of Literary Reading in America', Research Division Report \#46 (June 2004) based on Census Bureau findings in 1982, 1992, and 2002. This report is available as a PDF document at www.nea.gov/pub/ReadingAtRisk.pdf.

25. I am especially wary of this hazard since similar claims about the audiobook revolution have been made prematurely even before the arrival of digital downloads. One such example is Sarah Kozloff's discussion of the American audiobook market in the mid-1990s, in 'Audio Books in a Visual Culture', Journal of American Culture 18.4 (1995), 83-95.

26. The source for the British estimate is Helen Nugent's 'Click Here for a Really Novel Way to Enjoy a Book', The Times 2 May 2006, 12. Worldwide figures cited here are taken from Aislinn McCormick, 'Together in Download Dreams', The Bookseller 5188 (22 July 2005), 42.

27. Damian Horner, 'Misled by E-books?' Bookseller 5233 (9 June 2006), 22.

28. Numerous other online audiobook providers throughout the UK are listed on the website maintained by the Audiobook Publishing Association: www.theapa.net.

29. Graham Clarke, The Photograph (Oxford: Oxford University Press, 1997), 18.

30. This publishing venture can be found at http://harpercollins.iamplify.com/ (accessed 26 March 2007). See Joel Rickett, 'Talkin' bout a Revolution', Bookseller 5253 (27 October 2006), 18.

31. Jeffrey Richards, Sir Henry Irving: A Victorian Actor and His World (London: Hambledon and London, 2005), 405.

32. Edward W. Cox, The Arts of Reading, Writing and Speaking, $3^{\text {rd }}$ edition (London: Frederick Warne, 1881), 140.

33. The best sources for these public readings are Collins, 'Reading Aloud' and Andrews, 59-67.

34. Introductions to the pedagogical uses of podcast technology include Will Richardson, Blogs, Wikis, Podcasts, and Other Powerful Web Tools for Classrooms (Thousand Oaks, CA: Corwin Press, 2006), Bard Williams, Educator's Podcast Guide (Eugene, OR: International Society for Technology in Education, 2007), and Kathleen P. King and Mark Gura, Podcasting for Teachers: Using a New Technology to Revolutionize Teaching and Learning (Charlotte, NC: Information Age Publishing, 2007).

35. One of the most popular recording software Audacity is available for free download from http://audacity.sourceforge.net.

36. LibriVox is not exceptional in its ambition to provide free audiobooks. Similar public-domain projects include Free Audio.org, literalsystems.org, podiobooks.com, spokenalex.org, and telltaleweekly.org.

37. For example, see comments made about the 'book-ness' of LibriVox audio recordings on the blog sponsored by the Institute for the Future of the Book at www.futureofthebook.org/blog/.

38. See Donald A. Low's 'Classic Fiction by Radio', in Radio Drama, ed. Peter Lewis (London: Longman, 1981), 134-142.

39. This phrase is one goal of the exercises recommended by Cicely Berry, former Voice Director for the Royal Shakespeare Company, in Your Voice and How to Use It, Revised edition (London: Virgin Books, 1975; 1994), 123.

40. Collins, 475, 483, 483.

41. Kent, 23. 
42. There have been a number of recent Higher Education initiatives at North American and British universities designed to make use of podcasting technology for pedagogical purposes. In 2004, Duke University distributed a free iPod to all 1,650 of its first-year students as part of an ambitious programme of mobile learning (see 'Duke University iPod First-Year Experience' at http://cit.duke.edu/pdf/ipod_initiative_04_05.pdf). Other institutions established partnerships with Apple in order to make available recordings from lectures, seminars, events, concerts, and sports to the general public through iTunes U, an academic version of Apple's iTunes store (see Apple's education website: www.apple.com/education/products/ipod/itunes_u.html). For more on podcasting in Higher Education, see the reports put out by Educause, an association promoting the use of information technology in Higher Education, such as Gardner Campbell, 'There's Something in the Air: Podcasting in Education', EDUCAUSE Review (Nov/Dec 2005), 33-46.

43. Kent, 109, and Field, 69.

44. Harry Furniss reports this conversation between George Dolby and an unnamed member of the audience during the American tour, in Some Victorian Men, 196.

45. Field, 69-70.

46. W.P. Frith, My Autobiography and Reminiscences., Eighth Edition (London: Richard Bentley and Son, 1890), 210.

47. Quoted in Collins, 196.

48. See Collins, 195.

49. See the discussion of technical literacy among students in Marc Prensky, 'Digital Natives', from 'On the Horizon', 9.5 (October 2001), 1.

50. McLuhan, Understanding Media: The Extensions of Man (London: Routledge, 2001), 7 .

51. My own pedagogical initiative 'Plot-Casting: Using Student-Generated Podcasts for Learning and Teaching Literature' is currently devising a model of good practice for creating audiobooks in the classroom at the University of Leeds.

52. Denis Donoghue, The Practice of Reading (New Haven: Yale University Press, 1998), 121. Ong's phrase is quoted on 121.

53. John Glavin, After Dickens: Reading, Adaptation and Performance (Cambridge: Cambridge University Press, 1999), 212.

54. The influence of theatre and visual media on Dickens' post-Victorian reception is addressed by the essays collected in John Glavin, ed., Dickens on Screen (Cambridge: Cambridge University Press, 2003).

55. See Roger Chartier's discussion of the social bonds formed through reading aloud during an earlier era in 'Leisure and Sociability: Reading Aloud in Early Modern Europe', trans. Carol Mossman, in Urban Life in the Renaissance, ed. Susan Zimmerman and Ronald F. E. Weissman (Newark: University of Delaware Press; London: Associated University Presses), 103-20.

56. See Sterne's discussion of the posthumous voice, 287-90.

57. The most influential formulation of this argument is still Max Horkheimer and Theodor W. Adorno's Dialectic of Enlightenment: Philosophical Fragments, ed. Gunzelin Schmid Noerr, Trans. Edmund Jephcott (Stanford: Stanford UP, 2002).

58. See the objections made against sound reproducibility in Sterne, 21.

59. Kenneth Fielding, ed., The Speeches of Charles Dickens (Oxford: Clarendon Press, 1960), 246. 


\section{New Digital Audiobooks and Old Ways of Reading}

60. See Michael Bull's discussion of auditory experience in everyday life, in Sounding Out the City: Personal Stereos and the Management of Everyday Life (Oxford: Berg, 2000).

61. Tim Crook uses this phrase to describe radio drama prior to digital technology in Radio Drama: Theory and Practice (London: Routledge, 1999), 7.

62. Dickens, A Christmas Carol: The Public Reading Version, ed. Philip Collins (New York: New York Public Library, 1971), xv.

63. Schafer, The Soundscape: Our Sonic Environment and the Tuning of the World (Rochester, Vermont: Destiny Books, 1994), 11.

64. Sterne, 162.

65. Quoted in Esther Tolkoff, 'The Art \& Craft of Narration', Audiofile: The Magazine for People Who Love Audiobooks, http://www.audiofilemagazine.com/features/A1267.html (accessed 26 March 2007).

66. Jason Camlot, 'Early Talking Books: Spoken Recordings and Recitation Anthologies, 1880-1920', Book History 6 (2003), 167.

67. See the sceptical accounts given by Sven Birkerts, 'Close Listening: The Metaphysics of Reading an Audio Book', Harper's Magazine 286.1712 (Jan 1993), 86-91 and Rand Richards Cooper, 'Can We Really Read with Our Ears? The "Wuthering” Truth about Novels on Tape', New York Times (6 June 1993), section 7, page 15 a.

68. See Alison Byerly, 'From Schoolroom to Stage: Reading Aloud and the Domestication of Victorian Theater', Culture and Education in Victorian England, ed. Patrick Scott and Pauline Fletcher (Lewisburg: Bucknell University Press; London: Associated University Presses, 1990), 125-41.

69. Bernstein, 8 .

70. Quoted in Furniss, 196.

71. Originally recorded on wax cylinders, Tennyson's reading is available from the BBC Online's 'Poetry Out Loud' forum at http://www.bbc.co.uk/arts/poetry/ outloud/tennyson.shtml.

72. Dickens, The Old Curiosity Shop, Part One, Narrated by Walter Covell (Portsmouth, Rhode Island: Jimcin Recordings, 2004), $2: 58: 18$.

DOI: $10.3366 / \mathrm{E} 1355550208000088$ 